\title{
A Content Analysis of Images of Novice Teacher Induction: First-Semester Themes
}

\author{
Jennifer R. Curry \\ Louisiana State University \\ Angela W. Webb \\ Louisiana State University \\ Samantha J. Latham \\ Louisiana State University
}

\begin{abstract}
The powerful nature of novice teachers' experiences in their first years of teaching has been well documented. However, the variance in novices' initial immersion in the school environment is largely dependent on perceived personal and professional support as well as the environmental inducements that lend to novice teachers' success in the classroom. For the purposes of this study, 72 participating novices, who were participants in an alternative certification program, drew representations of their current teaching environments. Of the 72 initial participants' pictures, 58 were used in this content analysis. The interrater analysis involving multiple documentation of codes between and among researches, revealed five themes from the novices' pictures: (a) concerns about students, (b) overwhelmed and struggling, (c) relationships with others, (d) concerns about education quality and excessive accountability, and (e) issues with administration. Implications are provided.
\end{abstract}

Keywords: teacher induction, content analysis, mentoring, professional development

\section{Introduction}

In this article, we focus on the powerful nature of novice teachers' perceptions of their first-semester experience. There has been some variance in how the term novice teacher has been used in teacher education and educational leadership literature. For example, Kim and Roth (2011) define a novice teacher as any teacher with 5 years or less of experience. Conversely, some researchers narrow that definition to a teacher with less than 3 years of experience (Barrett et al., 2002). For this study, we collected drawings from novices within their first semester of teaching. Moreover, induction is a term used to describe "the initial stage or phase of one's career, or to the system of support that may be provided during that phase" (Strong, 2009, p. 6).

\section{Statement and Prevalence of the Problem}

In 2009, there were a total of 3,404,500 teachers in the United States, a number that continues to grow annually (National Center for Education Statistics [NCES], 2008). However, despite expansion in the workforce, the attrition rate for teachers has also increased significantly over the last few decades, with research indicating that the highest turnover rates are among those in their first years of teaching (Ingersoll, Merrill, \& Stuckey, 2014). For example, Perda (2013) found that more than $41 \%$ of novice teachers left the profession within 5 years of entry. More alarmingly, because of the 
expanding workforce, and the subsequent increase in the number of new teachers entering education, there are consequently greater numbers leaving (Ingersoll et al., 2014a). For instance, there were around 6,000 first-year teachers who left after the 1987-1988 school year, yet almost 25,000 left the occupation after 1 year in 2007-2008, a dramatic increase of over $400 \%$ (Ingersoll et al., 2014a). The economic and educational impact of these losses can be hard to approximate; however, it is estimated that attrition costs between $\$ 4,365$ to $\$ 9,501$ per teacher (Barnes, Crowe, \& Schaefer, 2007).

Additionally, evidence suggests a difference in retention between those prepared in a traditional teacher education program (i.e., bachelor of education) versus professionals trained through an alternative certification program, such as the novices in this present study. Of the beginning teachers who entered teaching after completing a traditional certification program, $90.0 \%$ were still teaching their second year and $84.0 \%$ by the fifth year (NCES, 2015). On the other hand, of the novice teachers who entered the profession through an alternative certification program, $90.1 \%$ were still teaching their second year, but only $79.2 \%$ were still teaching by the fifth year (NCES, 2015). These data suggest that beyond the degrees held by novices, the nature of training novices receive before entering teaching may impact their preparation level, and ultimately their commitment to the profession.

While traditional and alternative teacher preparation programs vary widely across states, "the content and substance of new teachers' preparation [matters] —especially the pedagogical preparation teachers acquired. Those with more pedagogy were far less likely to leave teaching after their first year on the job" (Ingersoll, Merrill, \& May, 2014, p. 29) and felt better prepared for the classroom (Ronfeldt, Schwartz, \& Jacob, 2014). Such pedagogical preparation includes methods coursework, practice teaching with feedback, and observation of other classroom teaching, with the positive impact of these practices demonstrated across beginning teachers regardless of their route to certification (Ingersoll et al. 2014b; Ronfeldt et al., 2014). Alternatively certified teachers, however, tend to receive their pedagogical preparation concurrent with the rough and tumble of their first year of teaching. It stands to reason that this would carry implications for their induction and retention.

Thus, in this particular study, we focused on the induction experiences of alternatively certified novice teachers rather than on the specifics or merits of any particular alternative certification program. A close look at the induction of this unique subset of teachers is warranted. Though alternative routes to certification accounted for only $29 \%$ of all teacher preparation programs nationally in 2011-2012, enrolling $10 \%$ of teacher candidates and producing $14 \%$ of program completers, the landscape of teacher preparation is drastically different in Louisiana, where this study was conducted (United States Department of Education [U.S. DOE], 2015). For the 2011-2012 academic year, Louisiana ranked fifth nationally in alternative route program enrollment (U.S. DOE, 2015). Specifically, alternative routes to teacher certification accounted for $45 \%$ of program enrollment and 53\% of program completers statewide (U.S. DOE, 2015). Given this, we explored alternatively certified novice teachers' depictions of the systems in which they worked, with particular attention paid to emergent themes across novices' perceptions during their first semester of teaching. 


\section{Novice Teachers}

Although all teachers experience stress and might struggle with balancing student learning outcomes in the contemporary context of schools (i.e., excessive assessment and testing, student needs), the unique experiences of novice teachers have been well documented. For example, Moir (1999) observed over 1,500 novice teachers and noted distinct patterns in how they mentally perceived and responded to the first year of teaching. She organized these patterns into five different phases: (a) anticipation, (b) survival, (c) disillusionment, (d) rejuvenation, and (e) reflection. As indicated by Moir, the anticipation phase occurs during the practical experience of teacher preparation (i.e., student teaching), and novices have an idealized view of the teaching role and are highly committed to their career. The anticipation phase generally lasts through the beginning weeks of the school year until novices really acclimate to the daily routine of being a teacher.

In the survival phase, novices spend a disproportionate amount of time related to curriculum planning and begin to feel overwhelmed by the demands of their work load (Moir, 1999). This stage generally lasts from a few weeks into the first semester until about 2 months. A sense of work-life balance is diminished during the survival stage as novices work more hours, yet often feel ineffective. The disconnect between teacher preparation and the reality of school life becomes apparent at this stage. During the disillusionment phase, novice teachers' stress increases as they are expected to teach, meet with parents, and receive their first instructional feedback from school administrators (Moir, 1999). As their efficacy and esteem drop in this stage, they have the increasing stress of criticism from parents, administrators, school board members, and the media. Social media may add another element of frustration. For example, having a classroom Facebook page may be a great source of sharing information where parents can openly talk about class activities and assignments. However, if parents use the Facebook page as an outlet to complain about classroom instruction, homework, or other class problems, then the access to social media might actually reduce the teacher's feelings of support. All of these stressors might impact the novice teacher and may lend to lower career commitment.

The rejuvenation phase, according to Moir (1999), generally occurs after the winter break when the novice teacher has had time to personally refresh through spending time in pleasurable activities (e.g., social events, rest) and returns to the school environment refocused. Novice teachers begin to look forward to breaks (e.g., spring break, summer) optimistically and, concomitantly, begin to focus on being more strategic in their classroom instruction and planning for the subsequent year. In this phase, they gain a greater degree of assuredness in their own capabilities.

The final phase, reflection, includes a personal assessment by the novice of the year's challenges, his/her strengths, and accomplishments. More importantly, during this phase, novices begin visioning their futures and the changes they will make to improve their own and students' success. Moir (1999) hoped that an understanding of these phases would help mentor teachers, administrators, and school colleagues better conceptualize the experiences of novice teachers so that positive interventions for support might be developed.

Other researchers have used Moir's (1999) framework. For example, Tait (2008) used this framework (final phase: reflection) in a qualitative inquiry of novice teacher resilience and personal efficacy. Mauer and Zimmerman (2000) reported results of a mentoring program designed to support novice teachers both formally and informally. Using Moir's phases as a foundation and rationale for the program, Mauer and Zimmerman tracked 23 teachers over a 4-year period and found that only one left during that time. Though Moir's framework has been used by other researchers, no one has suggested a needed revision or change to the identified phases as identified by Moir. 


\section{Teacher Induction}

Based on Strong's definition that induction is a system of support for novices, at the heart of induction lies the premise that, given even the best preparation, there remains significant knowledge and skills that novice teachers can only learn on the job (Bartell, 2005; Feiman-Nemser, 2003). Moir's (1999) phases of a first-year teacher's career, coupled with other research on teacher learning and development (see Darling-Hammond, \& Bransford, 2005; Feiman-Nemser, 2001), inform best practices for supporting and retaining novice teachers through induction. The school reform movement of the 1980s ushered in many such induction programs aimed at improving teacher retention and development (Ashburn, 1987), with the number of novice teachers receiving induction support increasing steadily in recent decades (Ingersoll, 2012; Smith \& Ingersoll, 2004). This is noteworthy, given the strong link between participation in an induction program and the likelihood of a novice teacher moving schools or leaving the profession after the first year (Ingersoll, 2006, 2012; Smith \& Ingersoll, 2004; Strong, 2009). Specifically, "the strength of the effect [of induction on teacher retention] depended on the types and number of supports that beginning teachers received" (Ingersoll, 2012, p. 50), with comprehensive induction that included multiple components having a stronger effect on whether novice teachers remained in the classroom (S. T. Bickmore \& Bickmore, 2010; Ingersoll, 2012; Strong, 2009).

Despite overwhelming support for induction and evidence of its impact on teacher retention, induction programs can vary greatly (Ingersoll, 2012; Smith \& Ingersoll, 2004; Villani, 2009). Specifically, induction programs can differ in duration; whether mentors are full-time teachers, parttime mentors, or full-time mentors; mentor training; monetary remuneration for support providers; and funding, among other factors (Villani, 2009). Regardless of variations across induction programs, the core components of such programs are well agreed upon in the literature (Ingersoll, 2012; Smith \& Ingersoll, 2004; Villani, 2009). Beginning teachers should be afforded the opportunity to interact and engage with a mentor, who has been carefully selected (Bartell, 2005; Britton, Raizen, Paine, \& Huntley, 2000; Darling-Hammond \& Baratz-Snowden, 2005; Villani, 2009), trained and well supported (Berry, Hopkins-Thompson, \& Hoke, 2002; Britton et al, 2000; Darling-Hammond \& Baratz-Snowden, 2005; Moir, 2005; Villani, 2009), and purposefully paired with a novice teacher (Bartell, 2005; Johnson \& The Project on the Next Generation of Teachers, 2004).

Also, administrators should support the goals of induction as well as those who assist and mentor novice teachers, and foster a climate for productive dialogue between mentors and novices (Bartell, 2005). This can be accomplished by providing novices with less demanding or reduced teaching assignments, additional help, and staged expectations (Berry et al, 2002; Johnson \& The Project on the Next Generation of Teachers, 2004; Villani, 2009). Further induction support can include participation in seminars for novice teachers, common planning or collaboration time with colleagues who teach the same subject, and assistance from a teacher's aide (Ingersoll, 2006, 2012). Of such induction components, having a mentor teacher in the same subject area and having common planning or collaboration time with subject-area colleagues had the strongest effect on teacher retention (Ingersoll, 2012), with more comprehensive induction programs correlating with better retention (Ingersoll, 2012; Ingersoll \& Strong, 2011; Strong, 2009). Moreover, based on NCES (2015) data, mentorship matters. Specifically, of the beginning public school teachers assigned a mentor during their first year of teaching, 91.6\% were still teaching their second year (2008-2009) and $85.5 \%$ were teaching their fifth year (2011-2012). This is a stark contrast to those not assigned a mentor their first year, with only $83.6 \%$ of those beginning public school teachers returning the second year, and $71.4 \%$ still teaching their fifth year. These data further indicate a positive correlation between mentor programs and retention (NCES, 2015). 
The impacts of induction programs extend beyond teacher retention, though. Based on metaanalyses of research on teacher induction, induction affected novice teachers' practice and student achievement as well (Ingersoll, 2012; Ingersoll \& Strong, 2011; Strong, 2009). Though findings related to teacher practice were mixed and, at times, contradictory, critical review of past research indicated that induction influenced the ways novice teachers worked in the classroom (Ingersoll, 2012; Ingersoll \& Strong, 2011; Strong, 2009). Specifically, novices

who participated in some kind of induction performed better at ... keeping students on task, developing workable lesson plans, using effective student questioning practices, adjusting classroom activities to meet students' interests, maintaining a positive classroom atmosphere, and demonstrating successful classroom management. (Ingersoll, 2012, p. 51)

Similarly, there is a possible positive connection between comprehensive induction and student achievement (Ingersoll, 2012; Ingersoll \& Strong, 2011; Strong, 2009), with students of novice teachers "who participated in some kind of induction [having] higher scores, or gains, on academic achievement tests" (Ingersoll, 2012, p. 51).

\section{Personal and Professional Needs}

Induction processes that are formal, structured, planned, and that integrate multiple elements appear to be the most successful in promoting novice teacher career satisfaction and retention (S. T. Bickmore \& Bickmore, 2010; D. L. Bickmore \& Curry, 2013; Smith \& Ingersoll, 2004). Such elements are tailored to meet the personal and professional needs of novices. Personal needs for novice teachers include positive interpersonal relationships with colleagues; progressive collaborations with administrators, teachers, and parents; perceptions of open-door access to leadership; work-life balance; and positive school environment (Boyd et al., 2011; Curry \& Bickmore, 2012; Johnson, Kraft, \& Papay, 2012). Professional needs include an orientation to novices' professional roles, quality professional development, reduced workload, formative feedback on strengths and challenges through classroom observations, responsive administration, and mentorship that is formal and planned (S. T. Bickmore, \& Bickmore 2010; Feiman-Nemser, 2003; Smith \& Ingersoll, 2004; Wang \& Odell, 2002).

\section{Theoretical Framework}

Ecosystems theory (Bronfenbrenner, 1977, 1979) was the theoretical perspective that guided this research and the novice teachers' drawings. Based on Bronfenbrenner's Ecological Systems Theory, individuals develop in multiple systems; these systems are organic, constantly changing, and the relationship between individuals and systems are reciprocal (i.e., the system can affect the individual and the individual can also affect the system). Bronfenbrenner $(1977,1979)$ proposed that there are five systems that comprise the contexts in which individuals grow, change, and develop over time: (a) the microsystem, (b) mesosystem, (c) exosystem, (d) macrosystem, and (e) chronosystem.

The microsystem is the system comprising of an individual's immediate surroundings and is the most influential on development. For novice teachers, some examples of microsystems might include their classrooms, home life, and relationships with colleagues. Mesosystems are composed of the interactions between microsystems. An example of a mesosystem for a novice teacher might be if a child from the teacher's classroom (one microsystem) attends the same church the teacher attends (the church is another microsystem). The exosystem is a larger system that provides structure in the forms of resources, rules, and policies that support microsystems (such as school board policies and 
classroom materials or funds). The macrosystem includes cultural and social values, customs, and the economy. This system encapsulates cultural beliefs about education and teachers, the value of learning, and economic and social conditions affecting students and teachers. The chronosystem is in relation to how all of the other systems change over time. For teachers, the chronosystem might include how the teaching profession has changed over the years; for example, stressors such as increased accountability, economic challenges that have stagnated teacher pay, and adoption and implementation of Common Core State Standards have all impacted teachers and the teaching profession over time.

As part of their alternative certification program, novice teachers were in a workshop learning about developmental psychology when we collected their drawings. The participants received training on ecosystems and the multiple layers that impact individuals' development. For this study (and to check for sense making and understanding of developmental psychology), participants were asked to draw a picture representing how they currently view the systems they work in. They were told they could draw as many layers of their system (micro, meso, exo, macro, chrono) in their pictures as they wanted. As discussed in the next sections, we conducted a content analysis (CA) of the novice teachers' drawings to answer the following research questions: (a) How did novice teachers view the systems in which they worked? (b) Given the opportunity to depict their experiences through art, what common induction themes emerged about novice teachers' perceptions?

\section{Method}

\section{Participants}

Participants for this study were 72 novice teachers who had participated in an alternative teacher certification program, all in their first year of teaching at the time of data collection (see below for discussion of the certification program). School began for them in the first week of August, and these data were collected in early November, over 3 months into their first academic year. Fifty-eight participants' pictures were used in the CA of this study. Of these participants, $82 \%$ were female, $18 \%$ male, 76\% were White non-Hispanic, 22\% African American, 4\% Hispanic. Participants ranged in age from 24 to 57 years. The participants were in a wide range of educational settings including early childhood education, elementary education, special education, secondary education (math, science, English, foreign language, social studies).

\section{Context/Alternative Preparation}

All of the novices in this study had started an alternative teacher certification program in the summer of 2015 . The program had three main foci: (a) general teacher preparation and contentspecific workshops based on certification area, (b) practical teaching experience, and (c) certification. During the summer, novices participated in an intensive, 7-week institute, and concentrated on general teacher preparation and content-specific workshops meant to prepare them for the classroom. General teacher preparation included classroom management, child and adolescent developmental psychology, lesson planning, curriculum, and assessment; while content-specific workshops included topics specific to areas such as early childhood, elementary education, secondary education (English, science, math, social studies, foreign language) and special education. Next, during the academic year, novices completed 180 days of full-time teaching experience as the teacher of record and participated in monthly workshops. Finally, novices in the program earned their teaching certification based on satisfactory letters and evaluations from the school principal and practitioner advisor from the alternative certification program, and passing scores on PRAXIS exams (i.e., Principles of Learning and Teaching, content specialization exams). 


\section{Data Collection}

The researchers collected data for this study during the November workshop of the alternative certification program. During this workshop, novices were taught about developmental psychology and ecosystems theory (Bronfenbrenner, 1977, 1979). Specifically, prior to the drawings, the group discussed how systems impact individuals' growth and development in both positive and negative ways. After completing the training module on ecosystems theory, novices were given white paper and colored markers and were given a prompt to draw how they currently viewed the systems they work in and the individuals or groups they work with. They were asked to include what they considered to be challenges or supports or any combination of the two. These drawings served as the primary data source for this study.

\section{Data Analysis}

CA was used to analyze the data collected in this study. CA is the study of texts used in research and may be tailored to either qualitative or quantitative data analysis approaches (White \& Marsh, 2006). Specifically, Ahuvia (2001) noted that CAs have often been used in the past to quantify the content of texts but that that they are also a useful methodology for "counting interpretations of text" (p. 139). What constitutes text is broadly defined within the methodology of CA, including media such as obituaries, abstracts, web pages, written texts, transcripts, and advertisements (White \& Marsh, 2006). There are standards for defining and selecting texts (see Beaugrande \& Dressler, 1981, or White \& Marsh, 2006), and for identifying typologies of text (see Neuendorf, 2002), but most importantly, it is understood that the texts used are meant to convey meanings (White \& Marsh, 2006). In this study, participant drawings were the text analyzed and when coding the text in this study, researchers identified manifest and latent meanings. Manifest refers to obvious, or surfacelevel, meanings. Latent meanings are deeper, implicit, and may be subtle or understated (Ahuvia, 2001; Duriau, Reger, \& Pfarrer, 2007). CA is a very rigorous process in which multiple reviews of the texts being studied are done for creating code lists, collapsing codes, developing themes, and establishing replicability and validity (White \& Marsh, 2006).

In this study, as is noted by White and Marsh (2006), a qualitative approach was used in which research questions were formulated before the study, context was considered when determining meanings (specifically, the circumstances of beginning teachers in the modern era), and inductive, humanistic reasoning was used in determining codes and themes. Moreover, one key to successful CA is the use of interrater documentation of codes. In this case, all three researchers viewed the drawings separately and developed a list of potential codes from the themes present in the pictures. After, the code lists were compiled and attention was given to collapsing codes that were similar and removing duplicate codes to produce a finalized code list. The researchers then counted the number of times each code was used (see Table 1). 
Table 1: Final Codes and the Number of Times Each Was Present Across All Pictures

\begin{tabular}{lc}
\hline Code & $\begin{array}{c}\text { Number of Times } \\
\text { Code Is Present }\end{array}$ \\
\hline Cultural values in conflict with education & 9 \\
Lack of parent involvement & 13 \\
Disparate home/school life & 12 \\
Administration (punishing)-power & 2 \\
Administration (doesn't care) & 7 \\
Student behavior concerns & 16 \\
Life-work balance & 5 \\
Testing as stress & 10 \\
Testing does not equal quality & 7 \\
No personal or professional support & 11 \\
Overwhelmed & 12 \\
Curriculum concerns & 5 \\
Overwhelming student needs & 14 \\
Struggling (commitment, to apathy, to burnout) & 6 \\
Conflict with colleagues & 2 \\
Acrimonious relationship with parents & 11 \\
Legislation concerns & 3 \\
\hline
\end{tabular}

The researchers sorted through the pictures again, individually, using the final code list. The researchers found 58 pictures that contained at least one of the codes from the finalized code list. Next, the researchers counted the number of times the same code was noted by each of the researchers for each picture. For example, in 70 cases, all three of the researchers found the same codes in the same pictures. In 40 cases, two of the researchers identified the same codes in the same pictures. In 80 cases only one researcher identified a code in a particular picture. The researchers then reviewed all items where only one researcher identified a particular code on a picture and negotiated to determine if two or more were in agreement. Only codes on which two or more of the researchers agreed were counted in the final code list. The final code count consisted of 145 codes with agreement by two or three of the research team. Eleven of the pictures were not coded because either the meanings of the pictures were not discernible or were based solely on researcher interpretation, both of which might have potentially led to greater bias error in the data. Three of the 72 were identified as positive and not matching the finalized code list used to analyze the other 58 pictures. These three cases are highlighted in the discussion section.

\section{Findings}

Each of the final codes was collapsed into theme groups. A total of five themes were identified from novice teachers' drawings: (a) concerns about students, (b) overwhelmed and struggling, (c)

relationships with others, (d) concerns about education quality and excessive accountability, and (e) issues with administration. Please see Table 2 for a list of themes with included codes and code counts. Following is a description of each theme. 
Table 2: Themes, Codes Within Themes, Total Codes Within Theme

\begin{tabular}{llc}
\hline Theme & \multicolumn{1}{c}{ Codes Within Themes } & $\begin{array}{c}\text { Total Codes Within } \\
\text { Theme }\end{array}$ \\
\hline Concerns about students & $\begin{array}{l}\text { Overwhelming student needs, student } \\
\text { behavior concerns, cultural values in } \\
\text { conflict with education, disparate } \\
\text { home/school life }\end{array}$ & 51 \\
Overwhelmed and struggling & $\begin{array}{l}\text { No personal or professional support, } \\
\text { overwhelmed, struggling (commitment, to } \\
\text { apathy, to burnout), life-work balance }\end{array}$ & 34 \\
Relationships with others & $\begin{array}{l}\text { Lack of parent involvement, acrimonious } \\
\text { relationship with parents, conflict with } \\
\text { colleagues }\end{array}$ & 26 \\
Toncerns about education & $\begin{array}{l}\text { Testing as stress, testing does not equal } \\
\text { quality, curriculum concerns, legislation } \\
\text { concerns }\end{array}$ & 25 \\
Issues with administration & Administration (punishing)-power, \\
administration (doesn't care) & \\
Total \# of times codes &
\end{tabular}

\section{Concerns About Students}

Within the theme Concerns about Students, there were 51 pictorial representations captured across four codes: (a) overwhelming student needs, (b) student behavior concerns, (c) cultural values in conflict with education, and (d) disparate home/school life. The pictures revealed a range of concerns expressed by the novices including students struggling to learn, classroom violence and bullying, disrespectful students, students with disabilities, students coming to school hungry, and students' emotional issues such as low self-esteem, low self-worth, hopelessness, and helplessness. Moreover, concerns were expressed by the novices that the culture most students identified with did not reflect the same values as the school environment. This was illustrated in many ways such as the students' cultural values of money, fame, sports, entertainment, and cars. The values of the school that were seen as conflicting included sitting at a desk, reading, completing homework, and studious behavior. In most cases, there were numerous situations of this thematic category present in the same picture. This theme called into question the amount of support (i.e., professional development, administrator and mentor guidance) that these novice teachers received in positive behavioral interventions and support, response to intervention, applied behavior analysis, or other evidence-based practices for classroom behavior management. Very little was revealed by participants about the amount of mentorship, classroom observation with formative feedback, or other supports they were receiving to assist in overcoming these concerns.

Further, there did not appear to be a consistent opportunity for the novice teachers in this study to reflect upon, or process, positive aspects of students' home lives and cultures. In every picture where students' culture or family life values were depicted, they were done so from a negative, or deficit, perspective. For example, in one representative drawing a teacher depicted her students' home lives as filled with violence, sex, and drugs. Her illustration had notes and words indicating that students 
were lazy; had parents in jail; lacked food and baths, among other necessities; received no love; and had no motivation (see Figure 1). A major concern of this theme was that novices might struggle to employ effective culturally responsive teaching strategies if their views of students' cultures are pervasively negative rather than strengths based.

Finally, students' home lives, physical and emotional needs weighed heavily on the participants in this study. Novices might have wanted to help their students but may have experienced a low sense of efficacy for tackling the myriad issues they were facing in their new role. Dealing with the complications of students' learning struggles and emotional/psychological problems were predominant for these novice teachers. One representative drawing illustrated several concerns the teacher had for her student: "dad is too hard on him"; "needs proper diet"; "learning disability, student can't read, trouble expressing emotion"; and "sensitive, but unable to show it." Despite the prevalence of this issue (i.e., overwhelming student needs) for these novice teachers, it should be noted that there was no curriculum in the certification training they received to be able to adequately address these issues. Thus, ongoing professional development, administrative support, and mentorship in how to work effectively with students' emotional needs would have been a compelling component of induction for these novices. Please see Figure 1 for a picture representing this theme.

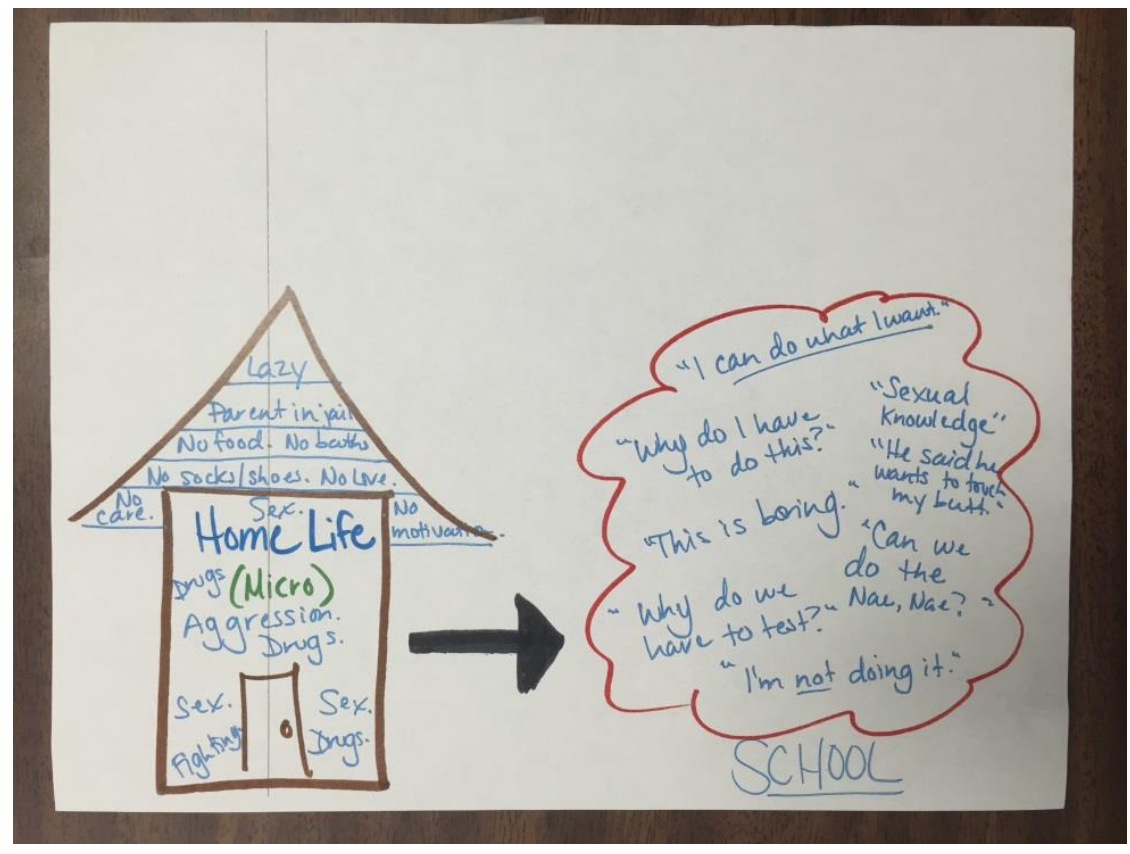

Figure 1: Picture Representing the Theme: Concerns About Students 


\section{Overwhelmed and Struggling}

The theme overwhelmed and struggling appeared 34 times in participants' pictures, and encompassed four code groups: (a) no personal or professional support, (b) overwhelmed, (c) struggling (commitment, to apathy, to burnout), and (d) life-work balance. This theme encapsulated issues such as the feeling that novices were overwhelmed with their workload, did not feel supported personally or professionally, and were struggling with feelings of desperation, hopelessness, helplessness, and their commitment to the teaching profession. The use of clocks was prevalent in this category to symbolize time passing quickly with an exorbitant amount of work left to complete. Work was often demonstrated as piling up and occurring day and night. Other symbolic representations in this category included isolation, whether the novice teacher represented her/himself working at home while the rest of the family was in a different room watching television together or on an island of her/his own. In one evocative/representative drawing from this theme, the novice depicted overload by placing her-/himself in the center of a circle surrounded by words describing school expectations (e.g., end-of-course exams, graduation, grades, etc.), student concerns (e.g., prom, homecoming, career decisions, college applications, specific courses, etc.), and students' cultures (e.g., \#BlackLivesMatter, peer pressure, temptation, bad influences, home life, etc.). Another image of overload featured an octopus and numerous balls of different types (e.g., footballs, baseballs, tennis balls, basketballs) being thrown at the octopus. To the sides, there were word bubbles saying, "Catch!" yet the octopus had caught none of the balls.

It is noteworthy that nearly all images in this theme depicting the novice as overwhelmed or struggling were accompanied by depictions of insufficient or lacking administrative and parental support. For example, the teacher who drew an island depicting isolation included these captions: "no support/advice," and "overwhelming/conflicting requirements without any help." In yet another image, the teacher labeled herself as "tired and overworked," as she navigated between student needs (e.g., student came to school angry), demanding yet unsupportive administration (e.g., "What are your interventions?"), and disengaged parents (e.g., "I don't shake hands," as parent drags student away). Novices portrayed working endlessly in the face of many obstacles and challenges without the personal or professional support they needed and desired.

This is the theme that most greatly demonstrated Moir's (1999) disillusionment phase. Novices' images within this theme exhibited myriad stressors against a backdrop of low self-efficacy and low self-esteem. Most notably, in a setting marked by "lack of parental involvement," "lack of caring from administration," and "incompetent leaders," among other things, the novice teacher was able to recognize the great potential in her students. Yet, this was not enough to keep her from crying out for help. As she wept, the teacher exclaimed, "OMG!" and "please help." "DEFEAT" was written in capitalized block letters and underlined twice, punctuating the disillusionment phase (see Figure 2). It should be noted that novices received support through the certification program from a practitioner advisor, who offered advice and feedback based on occasional teaching observations. This support, coupled with any support that might have been received from a school-based mentor, was still insufficient in addressing novices' feelings of struggle and being overwhelmed. Please see Figure 2 for a picture representing this theme. 


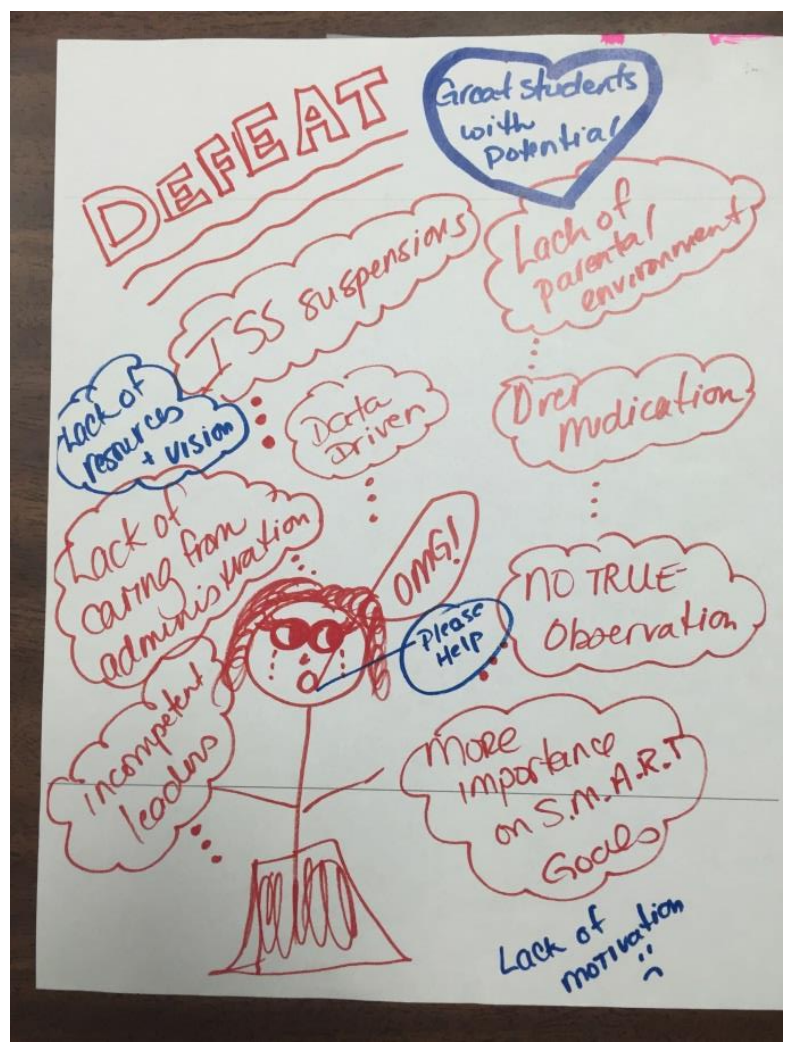

Figure 2: Picture Representing the Theme: Overwhelmed and Struggling

\section{Relationships With Others}

The theme relationships with others was prevalent 26 times and the codes included in this theme were (a) lack of parental involvement, (b) acrimonious relationships with parents, and (c) conflict with colleagues. Issues with parents were particularly concerning within this theme and ranged from pictures that included empty homes with no parents present, parents literally saying they did not care, parents who were unresponsive or inaccessible to teachers, parents in jail, parents abusing their children verbally or physically, and children with no food at home due to parental drug use. A lack of parental involvement was clearly displayed in a picture depicting a parent/teacher night signup sheet with over 100 spots available and only two names written down. The picture suggested that even when opportunities were made available by the school for parents to be an active part in their children's learning, they did not attend. The findings regarding parents in this theme highlight the problems inherent in teacher-parent relations when there is a lack of collaboration, mutual respect, and co-planning. Similarly, another picture was drawn illustrating the parent's brain as that of being in a fantasy land, with a unicorn and rainbow. These portrayals demonstrated a negative view toward the parents and their inability to recognize the reality of their children's educational situation. Another drawing within this theme depicted a student who did not care that he was being suspended and his mother who failed to see the importance of education because she dropped out in ninth grade herself. This not only illustrated a lack of parental involvement, but the importance of a parent's role in guiding and supporting their child's education. If academic achievement is not valued outside of school, a teacher has that much more of a challenge in the classroom connecting to students and engaging them in learning. 
However, problems can also arise when parental involvement becomes a barrier and leaves the teacher feeling powerless. An acrimonious parent-teacher relationship was portrayed in a picture where a mother was drawn large, in the center of the page, holding up her child on a pedestal, and towering over the teacher in the corner. The teacher appears intimidated and disempowered (see Figure 3). When novice teachers perceive that parents present a hostile attitude toward them this can manifest into behavioral problems with the student and an unwillingness to learn. Again, this highlights the importance of the parent's role, whether positive, negative, or lacking, in their child's education.

In terms of conflict with colleagues, novices depicted relationships on a spectrum from nonsupportive/noncollaborative to hostile. Some novices expressed that the school environments in which they worked had faculty that were competitive against each other (i.e., competing for test scores, professional recognition). One drawing in particular described the lack of support and camaraderie between the teachers leading to an environment where no one wanted to see one another succeed. This was further fueled by a lack of support and conflict resolution from the administration team. Given that collaboration with colleagues has been identified as a critical element of induction programs, this finding underscores the need for mentor teachers, instructional leaders, and administrators to create structures that promote collaboration such as weekly team meetings, planned group projects, and opportunities for team building. Please see Figure 3 for an example of a picture representing this theme category.

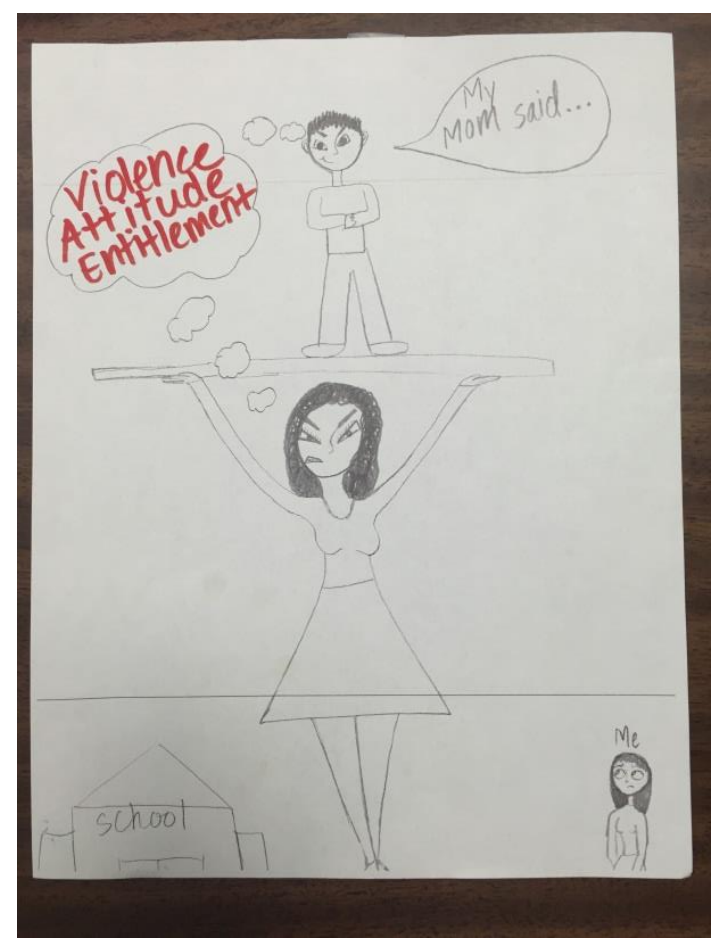

Figure 3: Picture Representing the Theme: Relationships With Others 


\section{Concerns About Education Quality and Accountability}

Within the theme concerns about education quality and accountability, novices expressed their strong concerns about the current educational environment 25 times. The codes within this theme included (a) testing as stress, (b) testing does not equal quality, (c) curriculum concerns, and (d) legislation concerns. Pictures that represented this theme included one-size-fits-all approaches to testing, administrators pushing more tests, calendars with testing days marked, unbalanced attention to tracking versus learning, and limited or insufficient time to help each student succeed.

This particular category seemed to underscore the novices' perceptions that testing is extreme and that real learning is not occurring in classrooms. Images of calendars emphasized the frequency of testing, with one particular depiction showing nearly as many testing days as instructional days in a month. On this same drawing, the novice included administrators proclaiming, "We must test, test ... Yes! ... More tests." While one novice showed that learning knowledge and life skills should outweigh specific standards, another represented how she felt her time was split between accountability and teaching. She drew a pie chart with $75 \%$ dedicated to student tracking (i.e., data) and $25 \%$ dedicated to student learning (i.e., instruction). Overall, novices left little room for interpretation as they expressed their views of testing. As one characterized, "testing $\neq$ measure of learning." Given these sentiments, it was unsurprising that testing was a source of stress for the novice teachers in this study. A representative image showed data charts from testing in each subject area with the terms "IEP" (individualized education plan), "evals," "parents," and "behavior documenting" imposed over the data charts. There was a clock sketched in the corner of the novice's drawing, emphasizing the sense of urgency novices felt toward testing. Similarly, another novice portrayed the stress of frequent testing by illustrating that the common assessments developed and administered by the school district's central office put her in the dog house. Rather than being used formatively, these assessments were an indictment on her teaching and students' learning.

Not only did novices see frequent testing as a roadblock to meaningful learning, but the curriculum was also a barrier. This was illustrated by a novice's drawing of an open book, with "I am a scripted curriculum" written around the book. On the pages of the book, the novice wrote,

The lesson should be taught word for word as I say. When I say time is up, you must move on. Time doesn't allow any extra minutes for students who don't understand right away. Students are not taught based on their needs as individuals!

Another novice reiterated the responsibility she felt to adjust instruction to individual student needs with the caption, "Lesson plans subject to change." The most striking image depicting the rigidity of curriculum showed an arrow labeled, "Line starts here." At this arrow started a line of children, drawn in all shapes, sizes, and colors, wrapped around to a conveyor belt. Coming off the conveyor belt were boxes of identical shape and size labeled, "Education, qty. 1. One size fits all" (see Figure 4). This image punctuates novices' feelings that standardized curricula turn education into a factorylike setting that is unresponsive to individual student's needs and talents. As with our first theme, concerns with students, a major concern within this current theme was that increased emphasis on testing and standardized curricula will perpetuate instruction that is not culturally responsive, especially if novices lack training and support to do otherwise.

Finally, it was not lost on the novices that issues of testing and documentation stemmed from legislative mandates. Numerous images identified standardized testing, Individuals With Disabilities Education Act, the state's Act 833 pertaining to individualized education plans for students receiving special education services, and No Child Left Behind as government mandates. 
How these are put into practice was a source of stress and frustration for the novices in this study. As one characterized, state and federal governments passed laws regarding education yet had "no clue what goes on in a classroom." Meanwhile, the teacher had a large class size and only time to help those who struggled, leading her to wonder, "What about the others?" Please see Figure 4 for a picture representing this theme.

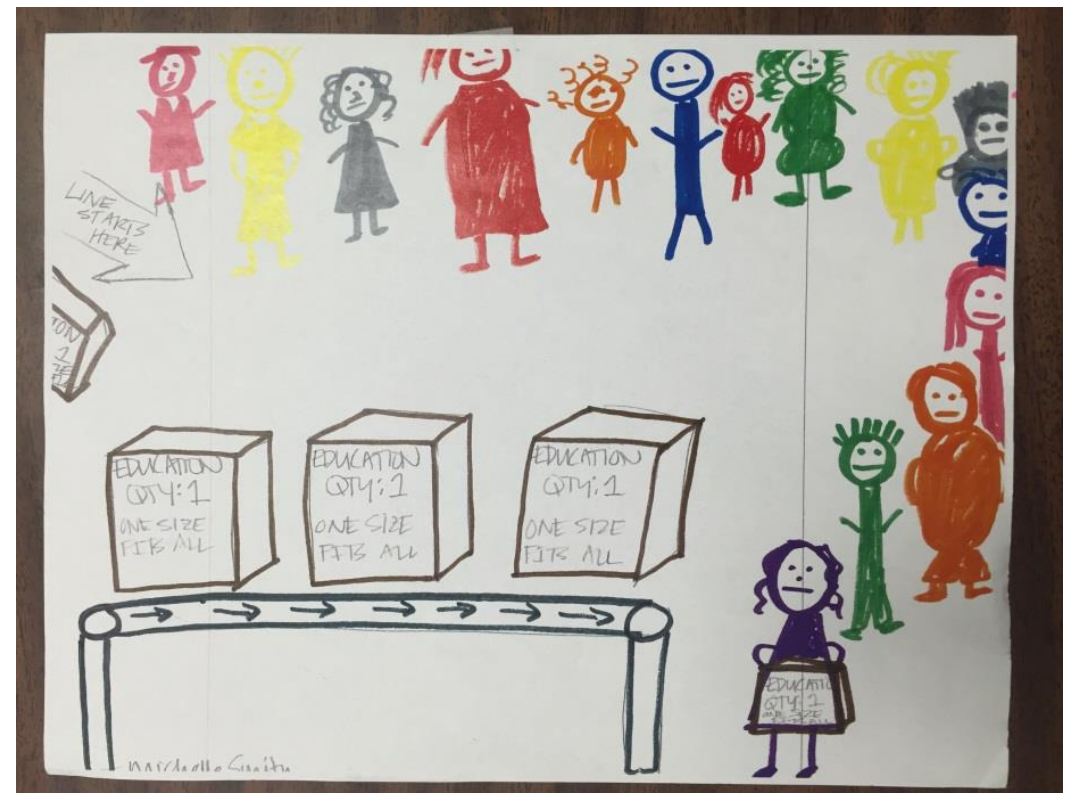

Figure 4: Picture Representing the Theme: Concerns About Education Quality and Accountability

\section{Issues With Administration}

This theme was present in nine drawings that fell into two main codes: (a) administration as punishing power and (b) administration as uncaring. In this category, administration encompassed the immediate school building administration and the local school board. The depiction of administration as punishing often had to do with testing and demanding more work from the novices (i.e., meetings, testing, student outcomes). For example, one picture portrayed the administration as an iron fist coming down on a brick wall and one picture went as far as portraying the administration as a paddle disciplining a defeated teacher. The depiction of administrators as uncaring manifested in numerous ways such as allowing negative student behavior to continue, ignoring the needs of the overwhelmed novices, and providing no additional resources or tangible support for the novice teachers. These ideas were highlighted in pictures where teachers described themselves as being on their own island or even drowning while the administration lounged by the pool not caring (see Figure 5). Considering these images within the framework of novices' professional and personal needs, the administrators were not seen by these participants as reducing workload, having open door access, or being responsive to the emotional needs of the novices. Rather, they appeared to be an added source of stress for the teachers and influenced their ability to be effective in the classrooms. Please see Figure 5 for an example of a picture representing this theme category. 


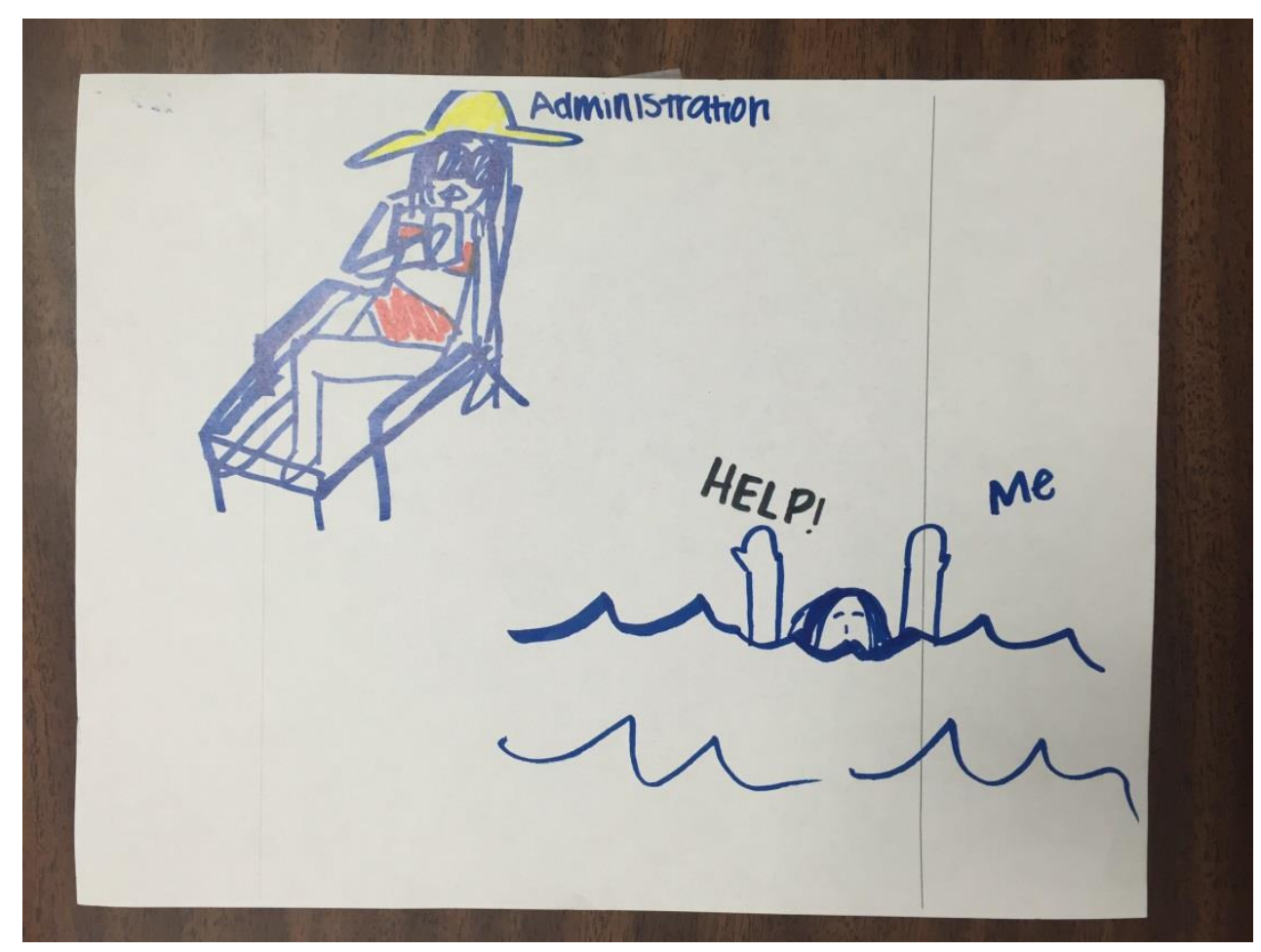

Figure 5: Picture Representing the Theme: Issues With Administration

\section{Discussion}

The novice teachers participating in this study mostly appeared to be in Moir's (1999) disillusionment stage. However, it is noteworthy to mention that there were actually three very positive pictures drawn that were not included in the findings in this manuscript as they were such stark outliers. In this discussion, we will disclose information on the outliers, review main findings from the 58 participants included in this study, and provide an overview of potential common threads between our research and the teacher induction literature.

\section{The Outliers}

Because there were only three seemingly positive pictures, we decided to exclude them from the larger data analysis and findings and mention them here in the discussion instead. In one of these three pictures, individuals of different sizes were holding hands under a large shining sun that is smiling down at them, and they were surrounded by positive words (Hope, Encouragement, Love) and quotes, "know then grow" and "Together we can change the world." Another depicted a tree growing in the sun with birds in a nest labeled as "parents \& school." The tree had many colorful leaves and the base (trunk) of the tree is noted as representing parents, school, and the school board. The only negative in the picture was a cloud and rain in one corner representing Common Core State Standards and grade-level expectations (accountability). The third positive picture portrayed the positive changes over time at one school. The word "REBIRTH" in all caps was at the top. On the left of the page was Hurricane Isaac with large rain drops containing words like, "Title 1, Change, Doubt, Relocation, Fear, FEMA." The center of the page had a picture of cycling winds with the 
words, "5 years and the winds of change." The right side depicted a new school under sunshine with positive words, "Community Involvement, PTA, New School, New Administration, Accountability." These three novices appeared to work in schools where, although they acknowledged some challenges, they clearly found support and structure that felt positive. Unlike the other 58 novices included in this study, they seemed more hopeful.

\section{Ecosystems}

The participants did look at the systems as impacting them in diverse ways. Most illustrated some form of systemic interaction. For example, microsystems interactions included things like students' behavior in the classroom or the principal-teacher relationship. Mesosystems were demonstrated through interactions between school and home life. Exosystems were depicted as accountability measures set by the school board or legislators. Finally, macrosystems were seen in terms of cultural values of teachers versus those of students, parents, and society at large. What was not apparent in these participants' drawing was a sense of reciprocity between themselves and the systems they drew. In other words, their ability to influence and change these systems was not seen. This lack of reciprocity may have indicated feelings of helplessness or powerlessness, hallmarks of the disillusionment phase identified and describe by Moir (1999).

\section{Primary Concerns}

Participants most often expressed concern regarding students through their drawings. Because most teacher preparation programs focus on content and pedagogy, it is not uncommon for novice teachers to struggle with classroom management and students' behavior. Moreover, many novices are shocked by cultural disparities between their own culture and that of the culture students identify with. The differences in social values, norms, and perspectives on education may be overwhelming for novices. Likewise, it can be challenging to create curriculum that is culturally appropriate when novices are working in a setting that does not allow for flexibility (Saunders, 2012), as could be the case in schools where teachers feel pressured to test more than teach. Furthermore, for teachers to design a meaningful curriculum, they must be able to teach beyond the scripted lesson plans and connect the learning to the students' interest, while making content relevant to diverse backgrounds (Bain, Newton, Kuster, \& Milbrandt, 2010). Having a time and place to reflect on culture, learn about culturally responsive teaching strategies, and to consider their own biases in terms of culture, parenting, and education might help novices to be more accepting and strengths focused in their work with students. It is important to note that although there was a training component on culture during the certification program's summer institute, there should also be ongoing opportunities for novices to consider culturally appropriate classroom strategies, develop awareness of their cultural biases, and reflect upon how culture impacts learning.

Concerns about curriculum, teaching to the test, and high-stakes accountability also seemed to frustrate novices. In many teacher education programs, learning to write and deliver lesson plans is a primary focus. This is also true for many alternative certification programs. In this case, the novices appeared to feel under great pressure about accountability. Understanding how to balance assessment of students' learning and promote quality education was an ongoing struggle. This concern needs to be a continual component of discussions with instructional leaders, mentors, and administrators to assist novices in learning to use assessment effectively while concomitantly engaging students in the learning process. 
Overall, these novices consistently displayed issues that lend to stress and potential burnout. Certainly, all careers have some degree of stress involved, but as has been noted by other researchers, for novices, job satisfaction and burnout lead to attrition (Kelly \& Northop, 2015). The amount of job satisfaction one feels might be related to the amount of problems they perceive in the systems where they work as well as the amount of support they receive. For example, Collie, Shapka, and Perry (2012) collected a sample of 664 elementary and secondary teachers. One key finding from that study was that teachers' perceptions of students' motivation to learn and classroom behavior had the largest impact when predicting teacher stress, teaching efficacy, and job satisfaction. In the current study, student concerns were prevalent throughout the sample and may have exacerbated the negative feelings and thoughts displayed by participants. Jones and Youngs (2012) found that burnout and subsequent teacher attrition were correlated with exhaustion and negative emotions. Conversely, positive emotions coupled with skill development (i.e., developing strategies for working with culturally diverse students, using assessment effectively) may promote teacher efficacy, career satisfaction, and commitment to teaching (Kelly \& Northrop, 2015).

None of the aforementioned concerns can be fully addressed without investment and advocacy from administrators. A compelling finding was that novices did not perceive administration as supportive. In some cases, they thought of administration as punishing and powerful, removed, unavailable, and dismissive of their concerns and struggles. These findings illuminated the importance of the relationship between administrators and novice teachers in working through novice teachers challenges. A true open door policy is helpful, but what is more beneficial, as was indicated in the literature, is structured and planned interactions with the principal, such as more formal observations, novice teacher check-ins, and monthly face-to-face meetings with a principal (S. T. Bickmore \& Bickmore, 2010).

\section{Limitations}

As with all research, it is important that the reader keep in mind limitations of the findings discussed in this manuscript. To begin with, the data reported here are strictly based on the perceptions and self-report of novice teachers. This data set does not represent administrative perspectives or that of colleagues, students, parents, school community members, etc. This data set also represented the novice teachers' perceptions at one particular point in time during the beginning of November; thus, the time of year could have had an effect.

A further limitation is that there was no triangulation of this data set. School districts and administrators were not asked to provide evidence of professional development, support, testing schedules, mentor lists, or other sources of information that may have been useful in corroborating the data reported here. None of the information contained here is meant to be generalized to larger populations, though the findings may be transferrable. It is important to remember that the novices in this study had participated in an intensive, 7-week alternative teacher preparation program prior to starting their jobs as full-time teachers. As all programs are unique and different, the findings here may be specific to the population participating in this study. 


\section{Implications}

In spite of the limitations, implications from this study are still relevant and important for principals and other instructional leaders to consider when hiring novice teachers. The importance of mentorship, collegial support, and parent involvement were underscored by these novices. Assisting new teachers in working with their mentors (through formal, planned processes) is crucial to their development. Mentoring novices requires professional development for mentors, time to provide mentorship, and evaluation of the mentorship program. In terms of collegiality, promoting a positive school culture, team building and incentivizing support of new colleagues appears to be an ongoing challenge. One principal recently shared with the first author that she gives a team prize once a month at her school. The number of documented team meetings, parent-teacher meetings, and team social events are all considered in her review and decision making. The winning team gets a faculty lunch provided by the principal. This lunch with the principal and the team is purely social. This principal shared that she does not always pay out of pocket for this incentive; she stated that there are restaurants that provide the meal as part of their support to schools in the community. Another principal enters mentor teachers that are rated highly by their mentees into a drawing for a gift certificate. Other principals have faculty awards that are given for mentor teachers.

Additionally, based on this study sample, more planning time and collaboration opportunities with colleagues might support novices in developing a closer connection with other faculty wherein they feel personally and professionally supported. This same finding has been noted by other induction scholars (Glazerman et al., 2010, Henry, Bastian, \& Fortner, 2011; Smith \& Ingersoll, 2004). Further, opportunities in preparation, throughout mentoring programs, and in professional development are needed to help novices understand and apply cultural pedagogy. Given time to reflect upon their own values, and how their values may create biases in the classroom, would be beneficial for this sample.

Finally, much has been written about teacher stress, which can lead to emotional exhaustion/instruction fatigue, burnout, and, eventually, impairment. Moreover, as stress increases, empathy and compassion decrease (Flook, Goldberg, Pinger, Bonus, \& Davidson, 2013), further distancing teachers and students and impacting educational outcomes and student achievement. Reducing novice teacher stress is imperative beyond retaining novices; it is also crucial to the affirmation of students and learning in classrooms. Reducing teacher stress is possible. Two potential ways beyond the supports already mentioned are to include professional development on mindfulness (see Flook et al., 2013) and implementation of social-emotional learning (see Collie et al., 2012).

\section{Conclusions}

In this study, a sample of 58 novice teachers' drawings, representing how they perceive the systems they work in, were analyzed. Codes and themes were established and discussed. Major themes included concerns about students, overwhelmed and struggling, relationships with others, concerns about education quality and excessive accountability, and issues with administration. Limitations were reviewed and implications were provided. Further research is needed on the transitions made by novice teachers, their perceptions, and the outcomes for students and schools when the needs of novice teachers are addressed. 


\section{References}

Ahuvia, A. (2001). Traditional, interpretive and reception based content analyses: Improving the ability of content analysis to address issues of pragmatic and theoretical concern. Social Indicators Research, 54, 139172. doi:10.1023/A:1011087813505

Ashburn, E. (1987). Current developments in teacher induction programs. Action in Teacher Education, 8, 4-44.

Bain, C., Newton, C., Kuster, D., \& Milbrandt, M. (2010). How do novice art teachers define and implement meaningful curriculum? Studies in Art Education, 51, 233-247. doi: $10.1080 / 00393541.2010 .11518805$

Barnes, G., Crowe, E., Schaefer, B. (2007). The cost of teacher turnover in five school districts. Washington, DC: National Commission on Teaching and America's Future.

Barrett, J., Jones, G., Mooney, E., Thornton, C., Cady, J., Guinee, P., \& Olson, J. (2002). Working with novice teachers: Challenges for professional development. Mathematics Teacher Education and Development, 4, 15-27. Retrieved from http://eric.ed.gov/?id=EJ658186

Bartell, A. C. (2005). Cultivating high-quality teaching through induction and mentoring. Thousand Oaks, CA: Corwin Press.

Beaugrande, R. D., \& Dressler W. U. (1981). Einfuhrung in die textlinguistik [Introduction to text linguistics]. Tubingen, Germany: Niemeyer.

Berry, B., Hopkins-Thompson, T., \& Hoke, M. (2002). Assessing and supporting new teachers: Lessons from the Southeast. Chapel Hill, NC: The Southeast Center for Teaching Quality at the University of North Carolina.

Bickmore, D. L., \& Curry, J. (2013). The induction of school counselors: Meeting personal and professional needs. Mentoring and Tutoring: Partnership in Learning, 21, 6-27. doi:10.1080/13611267.2013.784057

Bickmore, S. T., \& Bickmore, D. L. (2010). Revealing the administrator's role in the induction process: Novice teachers telling their stories. Journal of School Leadership, 20, 445-469. Retrieved from http://www.sciencedirect.com/science/article/pii/S0742051X09002418

Boyd, D., Grossman, P., Ing, M., Lankford, H., Loeb, S., \& Wyckoff, J. (2011). The influence of school administrators on teacher retention decisions. American Educational Research Journal, 48, 303-333. doi:10.3102/0002831210380788

Britton, E., Raizen, S., Paine, L., \& Huntley, M. A. (2000). More swimming, less sinking: Perspectives on teacher induction in the U.S. and abroad. Paper prepared for the meeting of the National Commission on Teaching Mathematics and Science in the 21st Century, March 6-7, 2000.

Bronfenbrenner, U. (1977). Toward an experimental ecology of human development. American Psychologist, 32, 513-531. doi:10.1037/0003-066X.32.7.513

Bronfenbrenner, U. (1979). The ecology of human development. Cambridge, MA: Harvard University Press.

Collie, R. J., Shapka, J. D., \& Perry, N. E. (2012). School climate and social-emotional learning: Predicting teacher stress, job satisfaction, and teaching efficacy. Journal of Educational Psychology, 104, 1189-1204. doi:10.1037/a0029356

Curry, J. R., \& Bickmore, D. L. (2012). School counselor induction and the importance of mattering. Professional School Counseling, 15, 110-122. doi:10.5330/PSC.n.2012-15.110 
Darling-Hammond, L., \& Baratz-Snowden. J. (Eds.). (2005). A good teacher in every classroom. San Francisco, CA: Jossey-Bass.

Darling-Hammond, L., \& Bransford, J. (2005). Preparing teachers for a changing world: What teachers should learn and be able to do. San Francisco, CA: John Wiley \& Sons, Inc.

Duriau, V. J., Reger, R. K., \& Pfarrer, M. D. (2007). A content analysis of the content analysis literature in organization studies: Research themes, data sources, and methodological refinements. Organizational Research Methods, 10, 5-34. doi:10.1177/1094428106289252

Feiman-Nemser, S. (2003). What new teachers need to learn. Educational Leadership, 60, 25-29.

Flook, L., Goldberg, S. B., Pinger, L., Bonus, K., \& Davidson, R. J. (2013). Mindfulness for teachers: A pilot study to assess effects on stress, burnout, and teaching efficacy. Mind, Brain, and Education, 7, 182-195. doi:10.1111/mbe.12026

Glazerman, S., Isenberg, E., Dolfin, S., Bleeker, M., Johnson, A., Grider, M., \& Jacobus, M. (2010). Impacts of comprehensive teacher induction: Final results from a randomized controlled study. Washington, DC: Institute of Education Science: National Center for Education Evaluation and Regional Assistance.

Henry, G. T., Bastian, K. C., \& Fortner, C. K. (2011). Stayers and leavers: Early-career teacher effectiveness and attrition. Educational Researcher, 40, 271-280. doi:10.3102/0013189X11419042

Ingersoll, R. (2006). Understanding supply and demand among mathematics and science teachers. In J. Rhoton \& P. Shane (Eds.), Teaching science in the 21st century (pp. 197-211). Arlington, VA: NSTA Press.

Ingersoll, R. (2012). Beginning teacher induction: What the data tell us. Phi Delta Kappan, 93, 4751.

Ingersoll, R., Merrill, L., \& May, H. (2014). What are the effects of teacher education and preparation on beginning teacher attrition? (Research report \#RR-82). Philadelphia, PA: Consortium for Policy Research in Education, University of Pennsylvania.

Ingersoll, R., Merrill, L., \& Stuckey, D. (2014). Seven trends: The transformation of the teaching force (Research Report \# RR-80). Philadelphia, PA: Consortium for Policy Research in Education. doi:10.12698/cpre.2014.rr80

Ingersoll, R., \& Strong, M. (2011). The impact of induction and mentoring programs for beginning teachers: A critical review of the research. Review of Education Research, 81, 201-233. doi:10.3102/0034654311403323

Johnson, S. M., Kraft, M. A., \& Papay, J. P. (2012). How context matters in high-need schools: The effects of teachers' working conditions on their professional satisfaction and their students' achievement. Teachers College Record, 114, 1-39.

Johnson, S. M., \& The Project on the Next Generation of Teachers. (2004). Finders and keepers: Helping new teachers survive and thrive in our schools. San Francisco, CA: Jossey Bass.

Jones, N., \& Youngs, P. (2012). Attitudes and affect: Daily emotions and their association with the commitment and burnout of beginning teachers. Teachers College Record, 114, 1-36. Retrieved from http://www.tcrecord.org/ExecSummary.asp?contentid=16240

Kelly, S., \& Northrop, L. (2015). Early career outcomes for the "best and the brightest": Selectivity, satisfaction, and attrition in the beginning teacher longitudinal study. American Education Research Journal, 52, 624-656. doi:10.3102/0002831215587352 
Kim, K., \& Roth, G. L. (2011). Novice teachers and their acquisition of work-related information. Current Issues in Education, 14.

Mauer, E., \& Zimmerman, E. (2000). Mentoring new teachers. Principal, 79, 26-28.

Moir, E. (1999). The stages of a teacher's first year. In M. Sherer (Ed.), A better beginning: Supporting and mentoring new teachers. Alexandria, VA: Association for Supervision and Curriculum Development.

National Center for Education Statistics (NCES). (2008). Schools and Staffing Survey. Washington, DC: U.S. Department of Education.

National Center for Education Statistics (NCES). (2015). Public school teacher attrition and mobility in the first five years: Results from the first through fifth waves of the 2007-08 beginning teacher longitudinal study. Washington, DC: U.S. Department of Education.

Neuendorf, K. A. (2002). The content analysis guidebook. Thousand Oaks, CA: Sage.

Perda, D. (2013). Transitions into and out of teaching: A longitudinal analysis of early career teacher turnover. Philadelphia, PA: University of Pennsylvania.

Ronfeldt, M., Schwartz, N., \& Jacob, B.A. (2014). Does preservice preparation matter? Examining an old question in new ways. Teachers College Record, 116, 1-46.

Saunders, J. M. (2012). Intersecting realities: A novice's attempts to use critical literacy to access her students' figured worlds. Multicultural Education, 19, 18-23. Retrieved from http://eric.ed.gov/?id=EJ1001520

Smith, T. M., \& Ingersoll, R. M. (2004). What are the effects of induction and mentoring on beginning teacher turnover? American Educational Research Journal, 41, 681-714. doi:10.3102/00028312041003681

Strong, M. (2009). Effective teacher induction and mentoring: Assessing the evidence. New York, NY: Teachers College.

Tait, M. (2008). Resilience as a contributor to novice teacher success, commitment, and retention. Teacher Education Quarterly, 35, 57-75.

U.S. Department of Education (DOE). (2015). Highly qualified teachers enrolled in programs providing alternative routes to teacher certification or licensure. Washington, DC: Author.

Villani, S. (2009). Comprehensive mentoring programs for new teachers: Models of induction and support (2nd ed.). Thousand Oaks, CA: Corwin.

Wang, J., \& Odell, S. J. (2002). Mentored learning to teach according to standards-based reform: A critical review. Review of Educational Research, 72, 481-546. doi:10.3102/00346543072003481

White, M. D., \& Marsh, E. E. (2006). Content analysis: A flexible methodology. Library Trends, 55, $22-45$. 
The Journal of Educational Research and Practice provides a forum for studies and dialogue that allows readers to better develop social change in the field of education and learning. Journal content may focus on educational issues of all ages and in all settings. It also presents peer-reviewed commentaries, book reviews, interviews of prominent individuals, and additional content. The objectives: We publish research and related content that examines current relevant educational issues and processes aimed at presenting readers with knowledge and showing how that knowledge can be used to impact social change in educational or learning environments. Additional content provides an opportunity for scholarly and professional dialogue regarding that content's usefulness in expanding the body of scholarly knowledge and increasing readers' effectiveness as educators. The journal also focuses on facilitating the activities of both researcher-practitioners and practitioner-researchers, providing optimal opportunities for interdisciplinary and collaborative thought through blogging and other communications.

Walden University Publishing: http://www.publishing.waldenu.edu 